\title{
Analysis of the VIT1 Promoter Activity in Developing Arabidopsis thaliana Plants
}

\begin{abstract}
Seçkin Eroğlu ${ }^{1, a, *}$
${ }^{1}$ Department of Biological Sciences, Middle East Technical University,06800 Ankara, Turkey

*Corresponding author

A R T I C L E I N F O A B S T R A C T

Research Article

Iron $(\mathrm{Fe})$ deficiency in plants is one of the widespread problems limiting agricultural production. Generating crops more tolerant to Fe deficiency by genetic engineering or breeding is of great interest but challenging due to the knowledge gaps in general plant Fe homeostasis. Although several genes involved in Fe homeostasis have been identified, characterization of their roles is mainly limited to specific organs at specific developmental stages of the plant, where their mutants show the most striking phenotype. Vacuolar Iron Transporter 1 (VIT1) is a well-known gene that has been characterized for its function in the mature seed of Arabidopsis thaliana. VIT1 is an Fe transporter that determines the correct distribution of Fe storage in this organ. The study aimed to explore new physiological functions for VIT1. As a first step, Arabidopsis thaliana plants that contain PromoterVIT1: GUS constructs were used to study the temporal and spatial expression of the gene throughout the plant's lifecycle. GUS histochemical staining revealed the VIT1 promoter is active in the mature leaves and mature reproductive organs. VIT1 promoter activity in the stamen increased developmentally and was limited to tapetum and guard cells in the pollen sac. In the female organ, VIT1 promoter activity increased as the pistil developed into a silique. Although all the silique exhibited staining, staining density was higher in the peduncle, replum, and stigma regions. Inside the developing silique, funicles were heavily stained. Furthermore, in silico analyses of VT1 transcriptome and protein levels confirmed flower and the silique are hot spots for VT1 activity. Thus, the results may suggest a possible involvement of VT1 protein in several stages of the reproductive system, specifically in the flowering and in the fruit development.
\end{abstract}

erogluseckin@gmail.com

(D) https://orcid.org/0000-0002-9494-7080|

\section{Introduction}

One of the widespread problems in agriculture is iron deficiency in plants. Plants often fail to retrieve enough $\mathrm{Fe}$ from the soil, posing a challenge in productivity and human health. Such plants cannot meet the Fe demand to achieve their full growth potential, causes a loss in yield (Abadía et al., 2011) and overaccumulation of harmful metals such as nickel and cadmium in their edible parts (Korshunova et al., 1999). Fe deficiency is especially prominent in calcareous soil, consisting of approximately one-third of all agricultural lands (Holloway et al., 2001). Therefore, to enhance plants in Fe uptake and storage, plant scientists have heavily explored $\mathrm{Fe}$ homeostasis, which led to the discovery of genes and physiological processes that involve them.

Fe is taken up from the soil by the root, distributed in the plant, and finally remobilized to the seed to give rise to the new generations. Root retrieves Fe from the soil with Iron-Regulated Transporter 1 (IRT1) protein on the plasma membrane of the outer root cells (Korshunova et al., 1999).
These cells transfer Fe to the inner root cells with the help of Natural Resistance Associated Macrophage Protein 1 (NRAMP1) (Castaings et al., 2016). In the vasculature, xylem and phloem transfer Fe associated with chelators, especially citrate for xylem, which is pumped into the xylem by Ferric Reductase Defective 3 (FRD3) and nicotianamine for phloem (Durrett et al., 2007; Schuler et al., 2012). Once translocated from root to shoot, Fe fuels various metabolic processes, notably those containing electron transport chain reactions in mitochondria and chloroplast of the leaves (Vigani et al., 2013). Part of the shoot Fe mobilizes from older tissues to the developing seeds in the siliques, in annual plants such as Arabidopsis thaliana, in a developmental process called senescence. Among the parts of the Arabidopsis seed, the majority of the Fe is diverted to the embryo (Eroglu et al., 2019). This Fe is built around the provasculature of the embryo with the help of Vacuolar Iron Transporter 1 (VT1) (Kim et al., 2006). Consequently, plants that do not have a functional VT1 protein lacks Fe stores in 
the provasculature (Kim et al., 2006). VT1 stands out among the other Fe homeostasis proteins as it is one of a handful of proteins that has successfully been used for biofortification of crops (Connorton et al., 2017; Narayanan et al., 2015, 2019).

VTI's structure has been extensively characterized. VT1 was first identified by homology to yeast CCC1 family proteins (Kim et al., 2006). It is well conserved in the plant kingdom (Eroglu et al., 2019). VT1 localized to the tonoplast and transported $\mathrm{Fe}$ and manganese when expressed in yeast (Kim et al., 2006). VTI's crystal structure indicated VTl has five transmembrane domains and functions as dimers (Kato et al., 2019). VT1's expression pattern, which was revealed by PromoterVT1: GUS lines, overlaps the localization of embryo Fe stores (Kim et al., 2006). Despite the extensive knowledge of VTl's structure, exploration of its physiological function has mostly been limited in the seed/seedling stage of Arabidopsis thaliana life cycle. A common strategy in searching for a function of a protein is to start exploring where and when its gene is preferentially expressed, following an examination of how knock-out mutant lines of this gene may behave physiologically different from the wild type, especially at stages and tissues where the gene expression was most remarkable. Therefore, to set the stage for investigating VTI's other physiological functions for future studies, $V T 1$ promoter activity in various tissues at various growth stages was examined by using PromoterVT1: GUS lines. The approach revealed that specific organs, tissues, and even cells show preferential $V T 1$ promoter activity, indicating an elusive function for VT1.

\section{Materials and Methods}

\section{Plant Material and Growth Conditions}

Two independent promoterVT1: GUS lines were obtained from Prof.Mary Lou Guerinot (Dartmouth College, Hanover, USA) (Kim et al., 2006). To observe growth on soil, seeds were sown onto standard potting soil (Substrat 1; Klasmann-Deilmann GmbH, Geeste, Germany). Pots were placed in a growth cabinet (Sanyo, Japan) set to $22^{\circ} \mathrm{C}$ day and $19^{\circ} \mathrm{C}$ night temperature and a $16 \mathrm{~h}$ light period with a light intensity of $140 \mu \mathrm{mol}$ photons $\mathrm{m}^{-2} \mathrm{~s}^{-1}$.

\section{Histochemical GUS Assay}

To perform GUS histochemical staining, all samples were vacuum infiltrated for an hour and then incubated at $37^{\circ} \mathrm{C}$ in a GUS reaction buffer containing $0.4 \mathrm{mg} \mathrm{mL}^{-1} 5$ bromo-4-chloro-3-indolyl- $\beta$-D-glucuronide, $50 \mathrm{mM}$ sodium phosphate ( $\mathrm{pH} 7.2$ ), and $0.5 \mathrm{mM}$ ferrocyanide, 0.5 $\mathrm{mM}$ ferricyanide and $0.1 \%$ Triton X-100 (Eroglu et al., 2017).

\section{In Silico Analyses}

For in silico transcriptome analysis of VT1, Genevestigator software was used (Hruz et al., 2008). All Arabidopsis microarray datasets were included in the study, and among them, ten organs that show the highest VT1 signal were sorted. Protein expression data is obtained from the Athena proteomics database (athena.proteomics.wzw.tum.de) (Mergner et al., 2020).

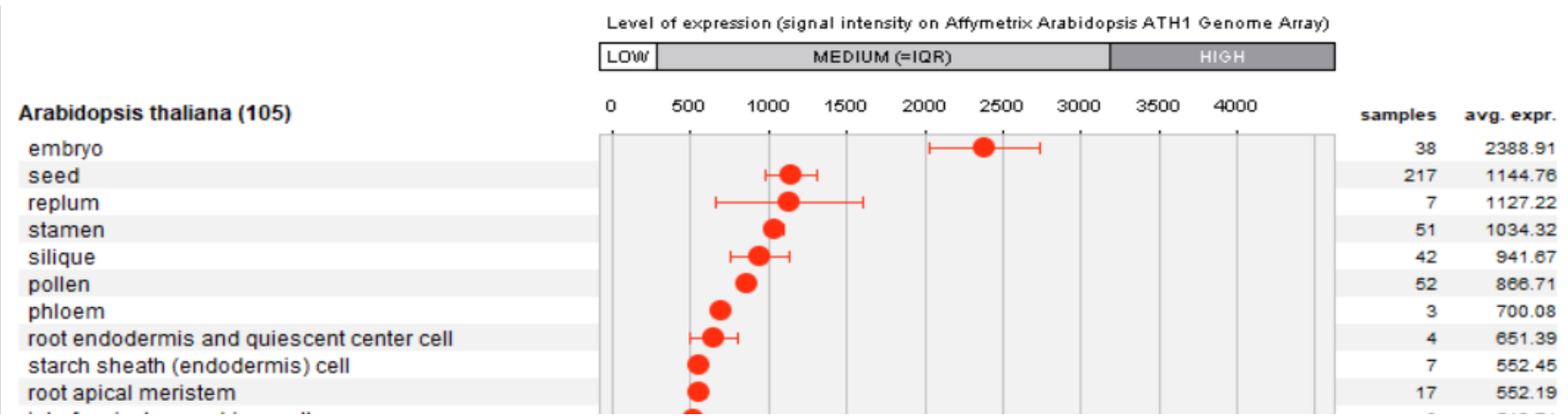

Figure 1. VT1's abundance in Arabidopsis thaliana's organs. Publicly available microarray analysis results were retrieved using Genevestigator software. Data show the top ten organs exhibiting the highest average VTI signal.

mature

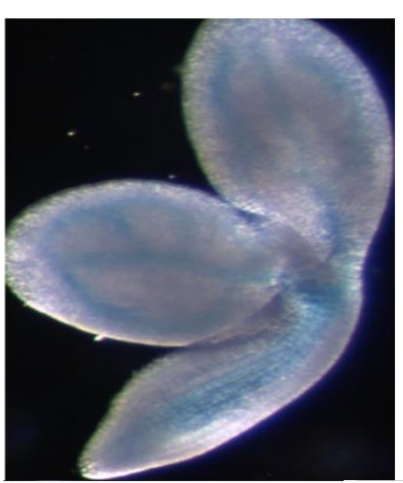

post-mature imbibed

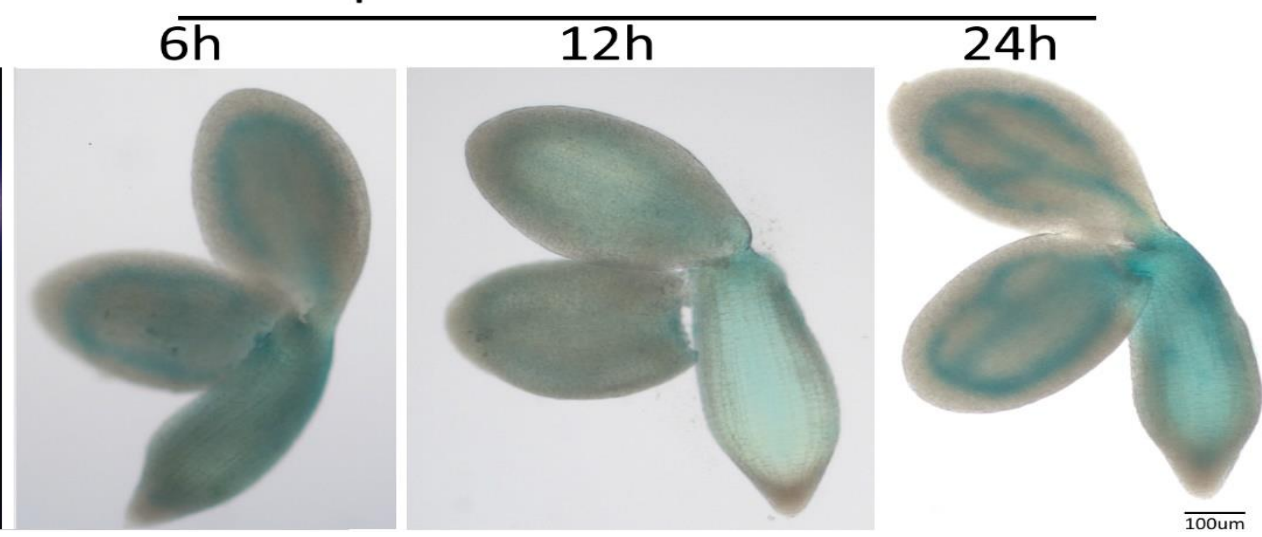

Figure 2. VT1 promoter activity in imbibed embryos. Mature drying siliques of PromoterVT1: GUS lines were dissected, and embryos were isolated(mature). Post-mature, dry seeds of the same line were imbibed in water for 6, 12 or 24 hours and embryos were isolated. All embryos were incubated in GUS staining solution for two hours and visualized under a light microscope. 


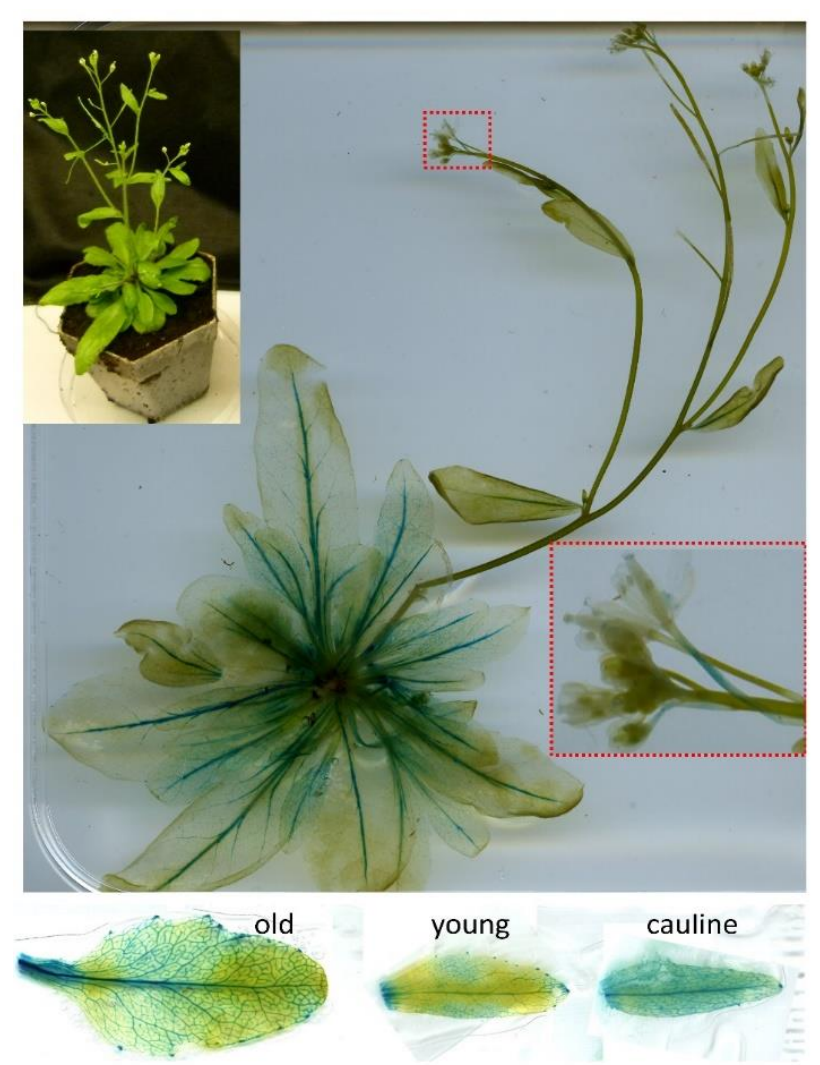

Figure 3. VT1 promoter activity in the bolting plants. PromoterVT1: GUS line was grown until the bolting stage (top left photo) and was stained in GUS solution. The whole shoot was incubated in GUS for 12 hours (middle photo) or 24 hours (only the dissected parts in the bottom panel). Old and young leaves from the rosette and cauline leaves were examined and photographed separately from the whole shoot (bottom right photo). Red box, close up to flowers.

\section{Results}

To investigate VT1 promoter activity in plant tissues, microarray databases were used (Figure 1). The curated microarray experiments in Genevestigator software's database showed the embryo part of the plant expresses VT1 highest, as expected. Besides embryo, flower organs express VTl in the second place. These organs included silique, stamen, and their subparts (i.e., replum and pollen). While the VT1 signal was approximately two times that of the flower, the software still grouped them in the mediumrange category. Thus, in silico analysis confirmed VT1 in the embryo and revealed $V T 1$ in flower.

Previous investigations show VTl promoter activity in developing embryos but not in postmature, desiccated ones (Eroglu et al., 2017). Next, VT1 promoter activity was investigated by histochemical GUS staining in the early phase of germination by imbibing seeds of PromoterVT1: GUS lines in a time coarse (Figure 2). The results showed that imbibed seed embryos express VT1 similar to postmature embryos regarding the localization (Figure 2).

Next, VT1 promoter activity in the whole shoot of bolting plants was assessed. After 12 hours of incubation, a bright blue color appeared on the vasculature region of the leaves (Figure 3). Among the leaves in the rosette, older leaves showed slightly higher staining than younger ones.
Twelve hours of incubation did not result in staining of the inflorescence, except the budding branches of the stem. The plant was also visualized after 24 hours of incubation. This time GUS staining was apparent on the minor veins of the leaf.

The promoter activity was also assessed also in the inflorescence after 24 hours of incubation, which resulted in heavy staining in older stamens (Figure 4). Stamens show staining only in the anthers. On top of the stamen, tissues inside the pollen sac, corresponding to tapetum exhibited staining. In contrast, pollens did not show staining (Figure 4E, black arrowheads). GUS staining accumulated in certain regions of the epidermis. The shape of the accumulation corresponded to the guard cells (Figure $4 \mathrm{~F}$, red arrowheads). In addition to stamen, younger branches showed staining. Therefore, the data suggest $V T 1$ 's preferential presence in developing flowers tapetum and guard cells of the pollen sac.

In silico analyses suggested VTl's presence in the silique, but it was not observed it in the carpel of the flower. $V T 1$ 's presence in the developing carpel/silique was examined (Figure 5A). The GUS staining result showed extensive staining in the developing siliques (Figure 5B), confirming the in silico expression analysis (Figure 1, Supplementary Figure 1). This staining was more intense in the internode/peduncle, replum, and stigma regions. Funicles showed intense staining inside the siliques (Figure 5C, D).

\section{Discussion}

$V T 1$ is a tonoplast $\mathrm{Fe}$ transporter. It builds up $\mathrm{Fe}$ reserves in the seed, but whether it also contributes to any other physiological processes in Arabidopsis thaliana has not been investigated. As a first step to build a hypothesis for such an investigation VT1 expression was assessed using transgenic lines that contain PromoterVT1: GUS constructs. Growth stages and organs that express VT1 were identified. These included the stamen of the flower and the silique, indicating a potential role of VTl protein in these organs.

Elucidating spatial and temporal expression patterns of already characterized genes often leads to discovering new physiological functions for the same genes. For example, MTP8 protein serves under Fe deficient conditions in the Arabidopsis roots. Still, a later realization of its expression in the seeds led to discovering a new role for it building up the manganese reserves in the seed embryo (Eroglu et al., 2016, 2017). Previous studies have reported VTI's critical role during the germination of seeds under stress conditions, while the results here may indicate an additional developmental role for VTI (Figure 4, 5).

The findings in this manuscript infer a role for VTl in the late stage of developing male and female organs of the plants. The male organ, anther, consists of a stamen and a filament that holds it. The male organ matures as the filament develops and stamen produces pollens inside the tapetum of the pollen sac. Mature stamens dehiscence to release the pollen and die soon after. The female organ, the pistil, receives the spores and gradually becomes a silique. $V T 1$ is expressed in the maturing stamen, specifically in the postmature stage at the tapetum and the guard cells of the stamen epidermis. 

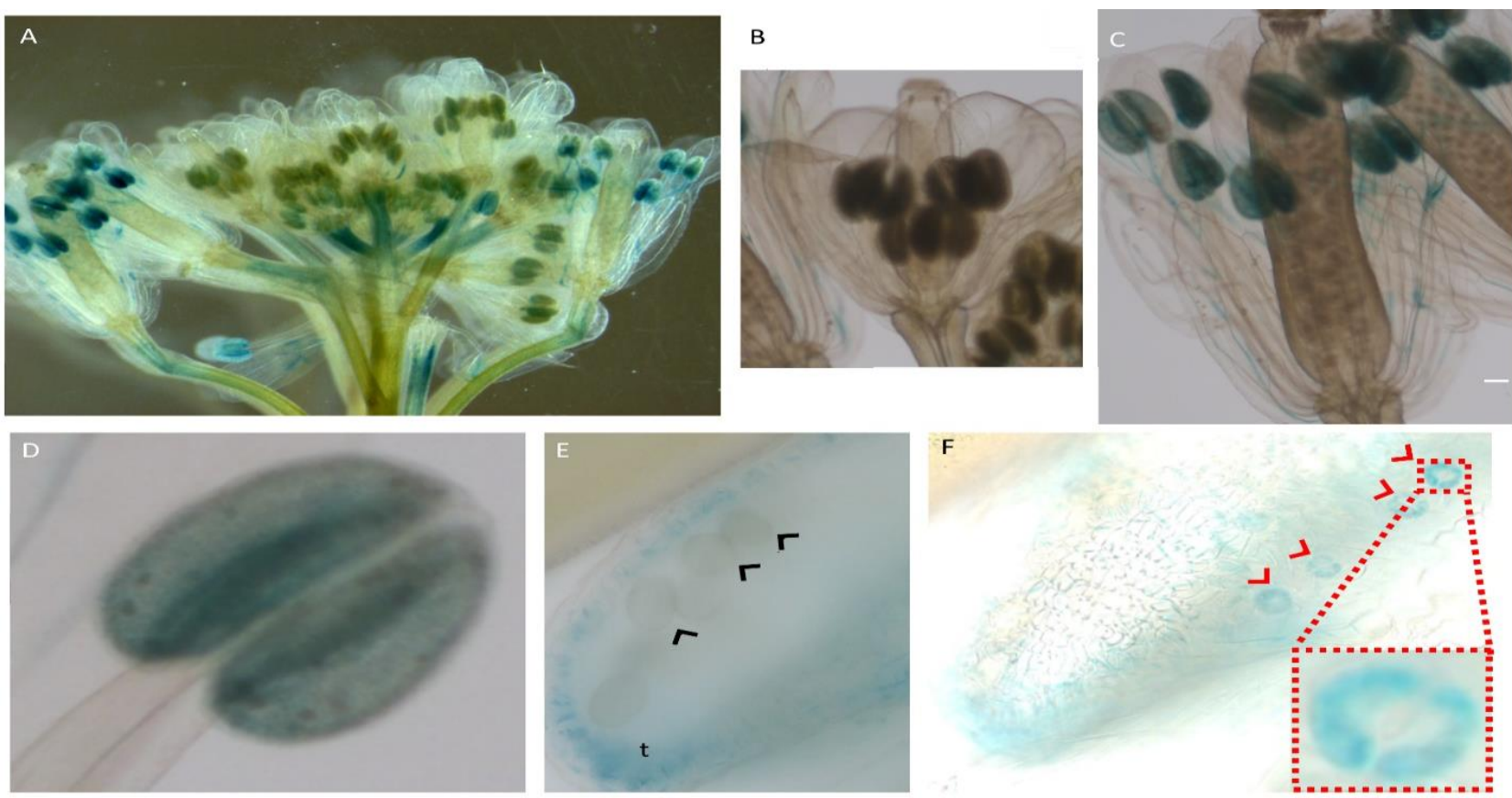

Figure 4. VT1 promoter activity in the stamen: PromoterVT1: GUS line inflorescence was incubated in GUS solution for 24 hours and visualized under the light microscope. A, cluster of flowers, note that the flowers in the middle are younger than the ones surrounding. B, young unopened flower close up. C, mature flower, close up, one day after flowering. D-F, the stamen of a mature flower. t, tapetum of a stamen. Black arrowheads, pollens. Red arrowheads, guard cells. Red box, guard cell, close up.
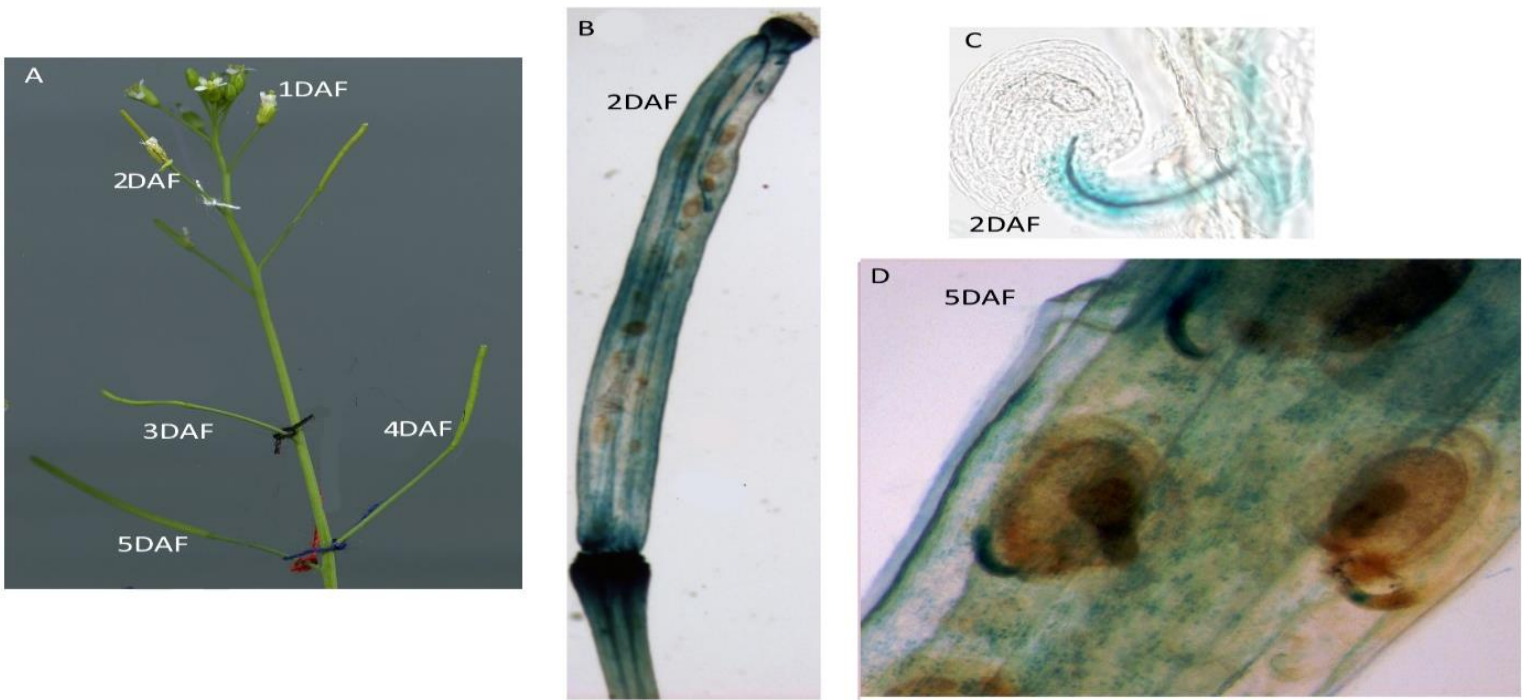

Figure 5: VT1 promoter activity in the silique following pollination: PromoterVT1: GUS line's developing siliques were incubated in GUS solution for 24 hours and visualized under the light microscope. A, untreated plant with growing siliques. B, silique; C, ovule, and funiculus; D, silique close up, developing seeds, and their funiculus were under focused. DAF: Day after flowering.

Table 1 . Summary of findings

\begin{tabular}{l|cc}
\hline & Sample & GUS level \\
\hline \multirow{3}{*}{ Seed } & Mature & $\mathrm{H}$ \\
& P. Dry & $\mathrm{H}$ \\
& P. Imbibed & $\mathrm{H}$ \\
\hline \multirow{2}{*}{ Leaf } & Rosette & M, more as the leaf ages, vasculature \\
& Cauline & M, vasculature \\
\hline \multirow{3}{*}{ Flower organ } & Petal & NA \\
& Carpel & NA \\
& Stamen & M, exclusive to tapatum and guard cells \\
& Siligue & M, especially in peduncle, stigma, and funiculus
\end{tabular}

$\mathrm{H}$, high; $\mathrm{M}$, medium; NA, not available; $\mathrm{P}$, postmature 
While in silico analysis pointed out VTI expression in the pollens (Figure 1), the GUS staining method failed to confirm it (Figure 4). However, developing pollens may express VT1 before dehiscence, but maybe the GUS solution could not infiltrate the intact pollen sac to reveal that. After the dehiscence, VT1 might function for nutrient recycling as a part of senescence in the male organ before it dies. VT1 is expressed in the pistil after pollination while pistil matures into the silique. The early developing embryos require $\mathrm{Fe}$ to meet their fast metabolisms' demand, which must be transported to the embryos via peduncle, the base of the pistil, to the silique, and from the silique to the funicle, then finally from funicle to the seed. VTl is active throughout this process, suggesting it might protect the cells from Fe-related ROS damage by sequestrating excess cytoplasmic $\mathrm{Fe}$ in the middle of this Fe trafficking between the mature plant and the nascent seed. Excess cytosolic Fe is a common ROS inducer that must be enclosed in organelles or vacuoles (Briat \& Lebrun, 1999). In summary, results revealed that VT1 is active in maturing female and male organs of the flower, suggesting a putative developmental role for $V T 1$ in flower following pollination (Table 1).

Here in this manuscript, the $V T 1$ promoter activity was analyzed. Results suggested VTl expression is not limited to the embryo of the seed. Further studies such as the comparison of wild type and VTI loss of function mutants may reveal new physiological roles for the VTl, sealing some gaps in plant Fe homeostasis to generate Fe-fortified plants.

\section{References}

Abadía J, Vázquez S, Rellán-Álvarez R, El-Jendoubi H, Abadía A, Álvarez-Fernández A, López-Millán AF. 2011. Towards a knowledge-based correction of iron chlorosis. Plant Physiology and Biochemistry, 49(5): 471-482. https://doi.org/10.1016/j.plaphy.2011.01.026

Briat JF, Lebrun M. 1999. Plant responses to metal toxicity. Comptes Rendus de l'Academie Des Sciences - Serie III, 322(1): 43-54. https://doi.org/10.1016/S0764-4469(99)800 $16-X$

Castaings L, Caquot A, Loubet S, Curie C. 2016. The highaffinity metal Transporters NRAMP1 and IRT1 Team up to Take up Iron under Sufficient Metal Provision. Scientific Reports, 6: 37222. https://doi.org/10.1038/srep37222

Connorton JM, Jones ER, Rodríguez-Ramiro I, Fairweather-Tait S, Uauy C, Balk J. 2017. Wheat vacuolar iron transporter TaVIT2 transports $\mathrm{Fe}$ and $\mathrm{Mn}$ and is effective for biofortification. Plant Physiology, 174(4): 2434-2444. https://doi.org/10.1104/pp.17.00672

Durrett TP, Gassmann W, Rogers EE. 2007. The FRD3-mediated efflux of citrate into the root vasculature is necessary for efficient iron translocation. Plant Physiology, 144(1): 197205. https://doi.org/10.1104/pp.107.097162

Eroglu S, Giehl RFH, Meier B, Takahashi M, Terada Y, Ignatyev K, Andresen E, Küpper H, Peiter E, Von Wirén N. 2017. Metal tolerance protein 8 mediates manganese homeostasis and iron reallocation during seed development and germination. Plant Physiology, 174(3): 1633-1647. https://doi.org/10.1104/pp.16.01646
Eroglu S, Karaca N, Vogel-Mikus K, Kavčič A, Filiz E, Tanyolac, B. 2019. The conservation of VT1-dependent iron distribution in seeds. Frontiers in Plant Science, 10. https://doi.org/10.3389/fpls.2019.00907

Eroglu S, Meier B, Von Wirén N, Peiter E. 2016. The vacuolar manganese transporter mtp8 determines tolerance to iron deficiency-induced chlorosis in arabidopsis. Plant Physiology, 170(2): 1030-1045. https://doi.org/10.1104/pp. 15.01194

Holloway RE, Bertrand I, Frischke AJ, Brace DM, Mclaughlin MJ, Shepperd W. 2001. Improving fertiliser efficiency on calcareous and alkaline soils with fluid sources of $\mathrm{P}, \mathrm{N}$ and Zn. Plant and Soil, 236(2): 209-219. https://doi.org/10.1023/ A:1012720909293

Hruz T, Laule O, Szabo G, Wessendorp F, Bleuler S, Oertle L, Widmayer P, Gruissem W, Zimmermann P. 2008. Genevestigator V3: A Reference Expression Database for the Meta-Analysis of Transcriptomes. Advances in Bioinformatics, 2008, 1-5. https://doi.org/10.1155/2008/42 0747

Kato T, Kumazaki K, Wada M, Taniguchi R, Nakane T, Yamashita K, Hirata K, Ishitani R, Ito K, Nishizawa T, Nureki O. 2019. Crystal structure of plant vacuolar iron transporter VT1. Nature Plants, 5(3): 308-315. https://doi. org/10.1038/s41477-019-0367-2

Kim SA, Punshon T, Lanzirotti A, Li A, Alonso JM, Ecker JR, Kaplan J, Guerinot M. Lou. 2006. Localization of iron in Arabidopsis seed requires the vacuolar membrane transporter VT1. Science, 314(5803): 1295-1298. https://doi.org/10. 1126/science. 1132563

Korshunova YO, Eide D, Clark WG, Guerinot M. Lou, Pakrasi, H. B. (1999). The IRT1 protein from Arabidopsis thaliana is a metal transporter with a broad substrate range. Plant Molecular Biology, 40(1): 37-44. https://doi.org/10.1023/ A: 1026438615520

Mergner J, Frejno M, List M, Papacek M, Chen X, Chaudhary A, Samaras P, Richter S, Shikata H, Messerer M, Lang D, Altmann S, Cyprys P, Zolg DP, Mathieson T, Bantscheff M, Hazarika RR, Schmidt T, Dawid C, Kuster B. 2020. Massspectrometry-based draft of the Arabidopsis proteome. Nature, 579(7799): 409-414. https://doi.org/10.1038/s4158 6-020-2094-2

Narayanan N, Beyene G, Chauhan RD, Gaitán-Solís E, Gehan J, Butts P, Siritunga D, Okwuonu I, Woll A, Jiménez-Aguilar DM, Boy E, Grusak MA, Anderson P, Taylor NJ. 2019. Biofortification of field-grown cassava by engineering expression of an iron transporter and ferritin. Nature Biotechnology, 37(2): 144-151. https://doi.org/10.1038/s415 87-018-0002-1

Narayanan N, Beyene G, Chauhan RD, Gaitán-Solis E, Grusak MA, Taylor N, Anderson P. 2015. Overexpression of Arabidopsis VTI increases accumulation of iron in cassava roots and stems. Plant Science, 240: 170-181. https://doi.org/ 10.1016/j.plantsci.2015.09.007

Schuler M, Rellán-Álvarez R, Fink-Straube C, Abadía J, Bauera P. 2012. Nicotianamine functions in the phloem-based transport of iron to sink organs, in pollen development and pollen tube growth in Arabidopsis. Plant Cell, 24(6): 23802400. https://doi.org/10.1105/tpc.112.099077

Vigani G, Zocchi G, Bashir K, Philippar K, Briat JF. 2013. Signals from chloroplasts and mitochondria for iron homeostasis regulation. Trends in Plant Science, 18(6): 305311. https://doi.org/10.1016/j.tplants.2013.01.006 